\title{
High temporal resolution NDVI phenology from micrometeorological radiation sensors
}

\author{
K. F. Huemmrich, ${ }^{1}$ T. A. Black, ${ }^{2}$ P. G. Jarvis, ${ }^{3}$ J. H. McCaughey, ${ }^{4}$ and F. G. Hall ${ }^{5}$
}

\begin{abstract}
The boreal forest is a region characterized by wide swings in temperature and light levels over the course of a year. This seasonal variability strongly effects the vegetation of this biome. Normalized difference vegetation index (NDVI) values were observed at daily timescales for key land cover types of the boreal forest, developing a more detailed description of seasonal changes in NDVI than could be produced from satellite data. NDVI values were calculated from tower-mounted photosynthetically active radiation (PAR) and global solar sensors measuring both incoming and reflected radiation above the canopies at four Boreal Ecosystem-Atmosphere Study (BOREAS) sites. Comparisons were made between the tower-based broadband hemispherical NDVI values and the narrowband nadir-viewed NDVI values from helicopter modular multiband radiometer (MMR). The comparisons indicate that the tower NDVI values are close to the MMR NDVIs in value for the BOREAS sites, but the range in tower NDVIs is not so great as in the MMR NDVIs. In 1996, BOREAS towers operated from before thaw to freeze-up, allowing a complete picture of growing season NDVI for fen, young jack pine, black spruce, and aspen sites. The tower-based NDVI time series display different patterns for each vegetation type, showing the effects of snow cover and vegetation green-up and senescence. Changes in solar zenith angles are shown to have little effect on the seasonal NDVI patterns.
\end{abstract}

\section{Introduction}

The seasonal change in the reflectance of landscapes has long been an important area of study in remote sensing. The spectral reflectance of the landscape is often expressed as an algebraic combination of spectral bands called vegetation indices. The most commonly used vegetation index in seasonal studies is the normalized difference vegetation index (NDVI). The pattern of seasonal change of NDVI provides an important description of the vegetation and has been used to describe a variety of landscape features, including vegetation type and productivity.

Landsat data have been used to study the phenology of NDVI. Multitemporal Landsat observations were used to determine vegetation type and productivity for land covers such as crops [Hall and Badwar, 1987; Badwar, 1984] and forests [Blair and Baumgardener, 1977; Badwar et al., 1986]. With a 16-18 day period between observations of a given location, Landsat is not able to generate frequent observations of vegetation seasonality. This weakness has been addressed in a study of the boreal forest by using growing degree days instead of time and combining data from multiple years [Hall et al.,

\footnotetext{
${ }^{1}$ University of Maryland, College Park, NASA Goddard Space Flight Center, Greenbelt, Maryland.

${ }^{2}$ Department of Soil Science, University of British Columbia, Vancouver, Canada.

${ }^{3}$ Institute of Ecology and Resource Management, University of Edinburgh, Edinburgh, Scotland.

${ }^{4}$ Department of Geography, Queen's University, Kingston, Ontario, Canada.

${ }^{5}$ NASA Goddard Space Flight Center, Greenbelt, Maryland.

Copyright 1999 by the American Geophysical Union.

Paper number 1999JD900164.

0148-0227/99/1999JD900164\$09.00
}

1991; Goetz and Prince, 1996]. In the First International Satellite Land Surface Climatology Project (ISLSCP) Field Experiment (FIFE) a detailed multitemporal time series for a grassland was created by combining NDVI data from both Landsat and SPOT satellites [Hall et al., 1992a; Goetz, 1997]. Few analyses of this type have been produced because of the difficulties and cost of acquiring and processing the large number of Landsat and SPOT images needed to get a detailed phenology.

The study of seasonal NDVI data blossomed with the use of data from the advanced very high resolution radiometer (AVHRR) that flies on the National Oceanic and Atmospheric Administration (NOAA) series of satellites. AVHRR observations provide views of the entire land surface of the Earth almost every day. Different vegetation types were found to have characteristic NDVI patterns through the year in the AVHRR data. Justice et al. [1985] used AVHRR data to study the phenology of vegetation in South America, Africa, and southern Asia. Also, monthly NDVI values through the year were summed and compared with existing maps of vegetation patterns. Tucker et al. [1985] classified vegetation cover types for Africa. Goward et al. [1985] looked at North American vegetation patterns. Both found a correspondence between the integrated NDVI distributions and the vegetation patterns. The seasonal variations in the AVHRR NDVI values have been used to classify vegetation globally [DeFries and Townshend, 1994], for the United States [Loveland et al., 1991], and for the BOREAS study area [Steyaret et al., 1997].

Beyond estimating cover type, it has been found that the NDVI values from AVHRR summed over a year were highly correlated with net primary productivity for major biomes in North and South America [Goward et al., 1985; Goward and Dye, 1987; Goward et al., 1987]. The AVHRR NDVI data have also been used to determine input parameters for vegetation 
productivity models [e.g., Running and Hunt, 1993; Prince and Goward, 1995; Field et al., 1995].

Other uses of seasonal variations in NDVI have shown correlations to atmospheric carbon dioxide concentrations [Tucker et al., 1986]. Also, changes in the length of the growing season at high latitudes have been detected over an 11 year period in the AVHRR data. These changes may be related to vegetation response to global climate change [Myneni et al., 1997].

While the AVHRR NDVI data have been very useful for the analysis of phenology, there are a number of difficulties in using these data. Some sources of error include cloud contamination and atmospheric aerosols, gases, and water vapor. All of these error sources tend to cause a decrease in the value of NDVI; so to minimize their effect, the AVHRR data are composited by selecting the largest value of NDVI over a selected time period [Holben, 1986]. Generally, the data are composited over periods of 10-30 days. This limits the temporal resolution of the data and causes a bias toward higher values during periods of change, such as the start and end of the growing season [Los et al., 1994; Holben, 1986]. The observations chosen in the compositing process may have varying view and solar angles from pixel to pixel, and these variations can effect the NDVI value [Goward et al., 1991; Goward and Huemmrich, 1992].

AVHRR data are also difficult to compare with surface observations due to the large pixel size. The observations have, at best, a $1 \mathrm{~km}$ resolution. However, because of variations in pixel size from different view angles and uncertainties in locating the multiple pixels in a temporal series the actual resolution may be 3-4 km [Steyaret et al., 1997].

The limitations on both temporal and spatial resolution of satellite observations of phenology make it difficult to compare directly with surface observations of plant processes. There are also few studies that have made frequent surface observations of vegetation reflectance to be able to produce a detailed ground-based NDVI phenology. One of the reasons detailed ground-based NDVI phenologies have not been collected is that most spectroradiometers used in remote sensing field work are not designed to operate automatically and to be exposed to the weather. Thus these observations require personnel to go out and make the measurements, limiting the number of observations that can be collected. In the case of forests there is also the problem of getting the instruments above the canopy.

As part of surface flux studies of forests, instruments to measure the radiative flux have been mounted on towers to make continuous observations of the forest canopy. AVHRR NDVI values have been shown to be correlated with albedos of photosynthetically active radiation (PAR) measured throughout a year above a red oak forest in Massachusetts [Sakai et al., 1997]. PAR and shortwave albedos have been shown to be sensitive to seasonal changes in leaf area index for this forest [Moore et al., 1996]. Sakai et al. [1997] also show that the PAR albedo is related to the canopy resistance to water vapor transport, linking radiative measurements and surface fluxes.

The Boreal Ecosystem-Atmosphere Study (BOREAS) experiment plan established towers in several different boreal vegetation types to collect surface flux and meteorology measurements [Sellers et al., 1995, 1997]. BOREAS provided the opportunity to produce detailed NDVI phenologies of several boreal vegetation types by using existing micrometeorological instruments in a novel way. The instrumentation on several of these towers included upward and downward viewing sensors for PAR and shortwave solar radiation. These common micrometeorological radiation sensors were used to calculate broadband NDVI values. As these sensors collected data continuously, it was straightforward to produce surface NDVI phenologies for specific vegetation types with a daily time step.

\section{Methods}

Data from four BOREAS flux tower sites were used in this study. These sites represent four very different boreal vegetation cover types: mature aspen, mature black spruce, young jack pine, and fen. The old aspen and old black spruce sites were in the southern study area in Saskatchewan, and the young jack pine and fen sites were in the northern study area in Manitoba. Each site had a tower that extended above the canopy for supporting eddy correlation and meteorological instrumentation. All of these sites had upward and downward viewing sensors measuring PAR and shortwave radiation mounted above the canopy. All towers used Li-Cor quantum sensors that measure the number of photons with wavelengths between 0.4 and $0.7 \mu \mathrm{m}$. The aspen, young jack pine, and fen sites used Eppley pyranometers that measure the shortwave solar irradiance between 0.285 and $2.8 \mu \mathrm{m}$. The old black spruce site used a Kipp and Zonen pyranometer that has a similar wavelength response as the Eppley pyranometers [Jarvis et al., 1997; McCaughey et al., 1997; Lafleur et al., 1997; Black et al., 1996].

The old aspen site had a mature aspen (Populus tremuloides) overstory with a hazelnut (Corylus cornuta) understory. The aspen trees were about 60 years old, $\sim 20 \mathrm{~m}$ in height, with a midsummer canopy cover of $\sim 90 \%$. The instruments were positioned at $36 \mathrm{~m}$ above the ground [Black et al., 1996].

The old black spruce site was dominated by mature black spruce (Picea mariana) with some tamarack (Larix laricina) occurring at the site. The spruce trees were over 100 years old. The understory consisted mostly of feather moss (Pleurozium schreberi) and Labrador tea (Ledum groenlandicum). Tree height was around $10 \mathrm{~m}$, with canopy cover of $\sim 55 \%$. The instruments were mounted at $16 \mathrm{~m}$ above the ground [Jarvis et al., 1997].

The young jack pine site consisted of jack pine (Pinus banksiana), which were less than 25 years old and only about $2.5 \mathrm{~m}$ tall. The understory was covered mostly by lichens (Cladina spp.). Instruments were attached to the tower at $\sim 11.5 \mathrm{~m}$ above ground [McCaughey et al., 1997].

The fen site was a wetland with no vegetation taller than a meter. Ground cover included bog birch (Betula pumila), buckbean (Menyanthes trifoliata), and sedges (Corex rostrata). Instruments were mounted $\sim 10.3 \mathrm{~m}$ above the ground [Lafleur et al., 1997].

Frequent observations of NDVI have been derived using data from the radiation sensors mounted on the flux towers. The normalized difference vegetation index (NDVI) is defined as

$$
\mathrm{NDVI}=\left(\rho_{\mathrm{NIR}}-\rho_{\mathrm{VIS}}\right) /\left(\rho_{\mathrm{NIR}}+\rho_{\mathrm{V}_{\mathrm{I}}}\right),
$$

where $\rho_{V_{13}}$ is the reflectance in the visible wavelengths, and $\rho_{\mathrm{NIR}}$ is the reflectance in the near-infrared wavelengths. In this study, measurements of incident and reflected PAR and incident and reflected shortwave radiation were used in the calculation of NDVI. First, the PAR measurements were converted from micromoles of photons to joules by multiplying by $0.25 \mathrm{~J}$ 
$\mu \mathrm{mol}^{-1}$. This conversion factor is based on the energy of photons of green light and converts the PAR data to units of watts $\mathrm{m}^{-2}$. PAR reflectance $\left(\rho_{\mathrm{PAR}}\right)$ was the ratio of reflected and incoming PAR ( $E_{\text {PARref }}$ and $E_{\text {PARin }}$ respectively),

$$
\rho_{\mathrm{PAR}}=\mathrm{E}_{\mathrm{PARTC}} / \mathrm{E}_{\mathrm{PARIn}} \text {. }
$$

To calculate an optical infrared reflectance $\left(\rho_{\text {OIR }}\right)$, the PAR irradiance values were subtracted from the shortwave irradiances for both incoming and reflected fluxes. Optical infrared reflectance was the reflected divided by the incoming of the differences of the irradiances. From the radiation instruments, PAR and optical infrared reflectances were calculated,

$$
\rho_{\text {OIR }}=\left(E_{\text {SWref }_{\text {ref }}}-E_{\text {PARref }}\right) /\left(E_{\text {SW in }}-E_{\text {PAR In }}\right)
$$

where $E_{S w_{r e f}}$ is the shortwave radiant exitance and $E_{S W_{1 n}}$ is the shortwave irradiance. These reflectances were substituted into (1) to calculate a broadband NDVI,

$$
\mathrm{NDVI}=\left(\rho_{\mathrm{OIR}}-\rho_{\mathrm{PAR}}\right) /\left(\rho_{\mathrm{OIR}}+\rho_{\mathrm{PAR}}\right) \text {. }
$$

NDVI values calculated from Landsat thematic mapper (TM) data use TM channels 3 and 4 with wavelength bands of 0.622-0.699 $\mu \mathrm{m}$ and 0.771-0.905 $\mu \mathrm{m}$, respectively. AVHRR NDVI values use AVHRR channels 1 and 2 with spectral ranges of $0.58-0.68 \mu \mathrm{m}$ and $0.725-1.1 \mu \mathrm{m}$. The broadband NDVI calculated with the micrometeorological sensors uses a PAR wavelength band of $0.4-0.7 \mu \mathrm{m}$ and an optical infrared band that is effectively between 0.7 and $2.8 \mu \mathrm{m}$ along with a $0.28-0.4 \mu \mathrm{m}$ addition. Because most of the radiant energy, both incident and reflected, in the optical infrared band is in the lower wavelengths of that band, i.e., in a similar spectral range as the AVHRR channel 2, we can expect the broadband NDVI to respond to the same vegetation effects as the satellite-derived NDVIs.

To evaluate the differences between the broadband NDVI and a typical narrowband NDVI, an analysis was performed using the helicopter-mounted multiband modular radiometer (MMR) data collected over the BOREAS sites [Loechel et al., 1997]. The helicopter made nadir observations of over 60 BOREAS sites, representing the different vegetation cover types found in the study area. These data were collected at solar zenith angles ranging from $32^{\circ}$ to $62^{\circ}$ throughout the growing season of 1994. MMR data were reported as reflected radiance and a reflectance for each channel; from these data the incoming irradiances were determined (see Table 1 for bandwidths of each MMR channel). Two different NDVI values were then calculated. The first was the narrowband NDVI $\left(\mathrm{NDVI}_{\mathrm{nb}}\right)$ which used reflectances from MMR channels 3 and 4. To calculate a broadband NDVI (NDVI $\left.{ }_{b b}\right)$, the radiances for channels $1-3$ and channels $4-7$ were summed. The incoming and reflected multiband radiances were used to calculate

Table 1. Barnes Multiband Module Radiometer Bandwidths

\begin{tabular}{lc} 
& Bandwidth, $\mu \mathrm{m}$ \\
\hline Channel 1 & $0.45-0.52$ \\
Channel 2 & $0.51-0.60$ \\
Channel 3 & $0.63-0.68$ \\
Channel 4 & $0.75-0.88$ \\
Channel 5 & $1.17-1.33$ \\
Channel 6 & $1.57-1.80$ \\
Channel 7 & $2.08-2.37$ \\
\hline
\end{tabular}

\section{BOREAS Helo MMR NDVI}

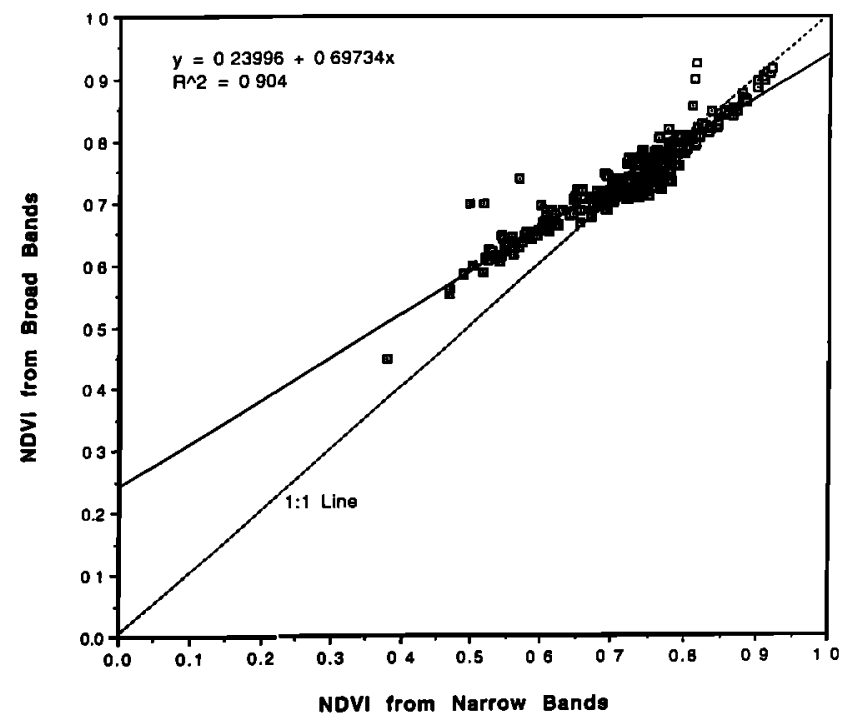

Figure 1. Broadband NDVI values compared to narrowband NDVI values. Data from the helicopter-mounted MMR for over 60 BOREAS sites collected through the growing season of 1994. The broadband NDVI used combinations of MMR bands 1, 2, and 3 for the visible band and MMR bands 4-7 for the near-infrared band in the NDVI calculation. The narrowband NDVI was calculated using only MMR bands 3 and 4 . The dashed line is the 1-to-1 line; the solid line is the least squares fit to the data.

broadband reflectances, and from the reflectances, $\mathrm{NDVI}_{\mathrm{bb}}$ was determined. The broadband MMR reflectances do not cover the full wavelength range of the micrometeorological instruments; however, most of the gaps between the MMR near-infrared bands occur in spectral regions where absorption by atmospheric water vapor allows very little energy to reach the Earth.

Figure 1 shows that there is a high correlation between broadband and narrowband NDVIs, with an $R^{2}$ of 0.9 . The slope of the regression line indicates that the broadband $\mathrm{NDVI}_{\mathrm{bb}}$ shows a smaller range in values than the narrowband $\mathrm{NDVI}_{\mathrm{nb}}$. The high correlation between the two different NDVIs indicates that the widening of the bands does not introduce significant amounts of noise for the BOREAS sites, although it does decrease the range of response observed.

NDVI values from the micrometeorological instruments were calculated for the times of helicopter observations of the sites. Figure 2 compares the MMR and flux tower NDVI (NDVI ${ }_{\text {rad }}$ ). This figure shows that the MMR narrowband $\mathrm{NDVI}_{\mathrm{nb}}$ appears to be better correlated to the MMR broadband $\mathrm{NDVI}_{\mathrm{bb}}$ than the flux tower broadband NDVI ${ }_{\mathrm{rad}}$. This is not too surprising since the two different MMR calculations both come from the same data. Differences in the NDVI values are due to different areas being viewed by the MMR and the flux tower instruments and that the MMR is a bidirectional reflectance measure, while the flux tower data represent hemispheric reflectances. The MMR gives a slightly higher broadband $\mathrm{NDVI}_{\mathrm{bb}}$ than the flux tower NDVI $\mathrm{Nad}_{\text {. }}$.

The helicopter MMR data show that NDVIs calculated from broad spectral bands respond to variations in vegetation in much the same way as narrowband NDVIs. 


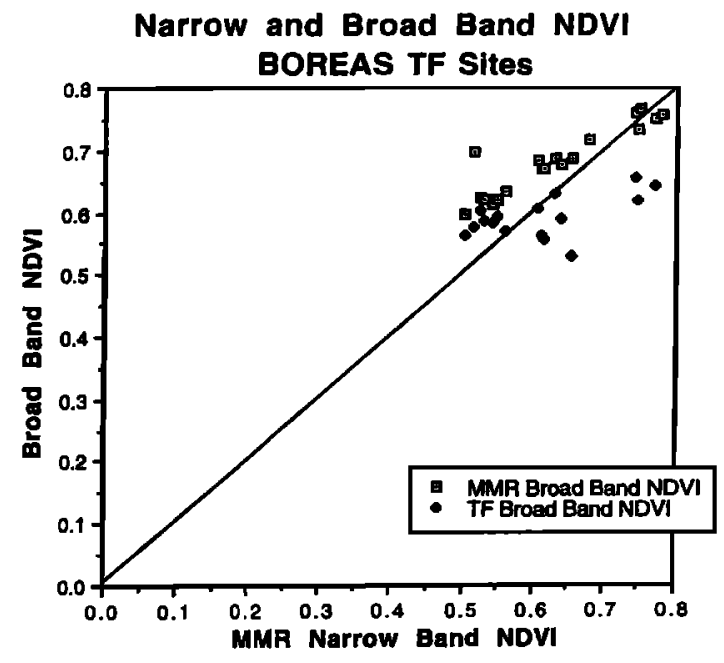

Figure 2. The $x$ axis is the narrowband NDVI from the helicopter-mounted MMR, as described in Figure 1. The squares are the corresponding broad band NDVI values from the MMR data. The diamonds are the NDVI values from the micrometeorological instruments, calculated for the times of helicopter observations of the sites. The line is the 1-to- 1 line.

\section{Results}

NDVI phenologies were produced for the sites at a daily time step. The data were reported as half hourly averages, and the values reported for 1400 LT for each day were used. This time was chosen to approximate the time of a NOAA satellite overpass. Data collected on cloudy days can produce spikes, generally showing larger NDVI values, in the time series. To eliminate these spikes, time series based only on data collected on clear days were created. Clear days were detected by predicting incident PAR for clear days based on the solar zenith angle at the time of the observations; then any day where the observed incident PAR was within $40 \mathrm{~W} \mathrm{~m}^{-2}$ of the predicted value were considered clear days. This method must be used with care near the end of the growing season when the incident PAR values become fairly small and the differences between clear and cloudy days shrink. In Figures 3-6 the NDVI points for every day are plotted with dashed lines, with solid lines connecting the points for clear days. After removing cloudy days, approximately a third of the points remain. These points produce a smooth seasonal NDVI curve.

Figure 3 shows daily NDVIs from 1996 for the old aspen site. To have shortwave irradiance data for this period, data from two different pyranometers were combined. Both instruments were mounted on the same tower, and when both were in operation, their measurements compared well with each other. The negative values of NDVI at the beginning of the time series were due to snow cover. The snow thawed and the NDVI increased to about 0.35 at day 134 (May 14). This was a period of bare ground and leafless trees that lasted until day 145 (May 25) when the NDVI curve began a sudden increase with the start of the growing season. NDVI increased over the following 20 day period up to 0.71 . The NDVI continued to increase but at a much slower pace, to a maximum value of 0.78 at day 219 (August 7). It then began a slow decline to day 269 (September 26) over which it dropped to 0.70 . After this day there was an accelerating decline with a sudden drop-off after day 277 (October 1). The early part of the decline in NDVI seemed due to an increase in PAR reflectance which may be due to leaf color changes, and the sudden drop-off may occur with the loss of leaves causing dramatic changes in both the PAR and the infrared bands. After the autumn NDVI drop, it settled around a value of about 0.39 for days 286-297 (October 13-24). This is another period of leafless trees, but this autumn period had a higher NDVI than the springtime leaf-off period. This may be because the newly fallen leaves have not broken down yet and are still scattering near IR radiation causing higher ND-

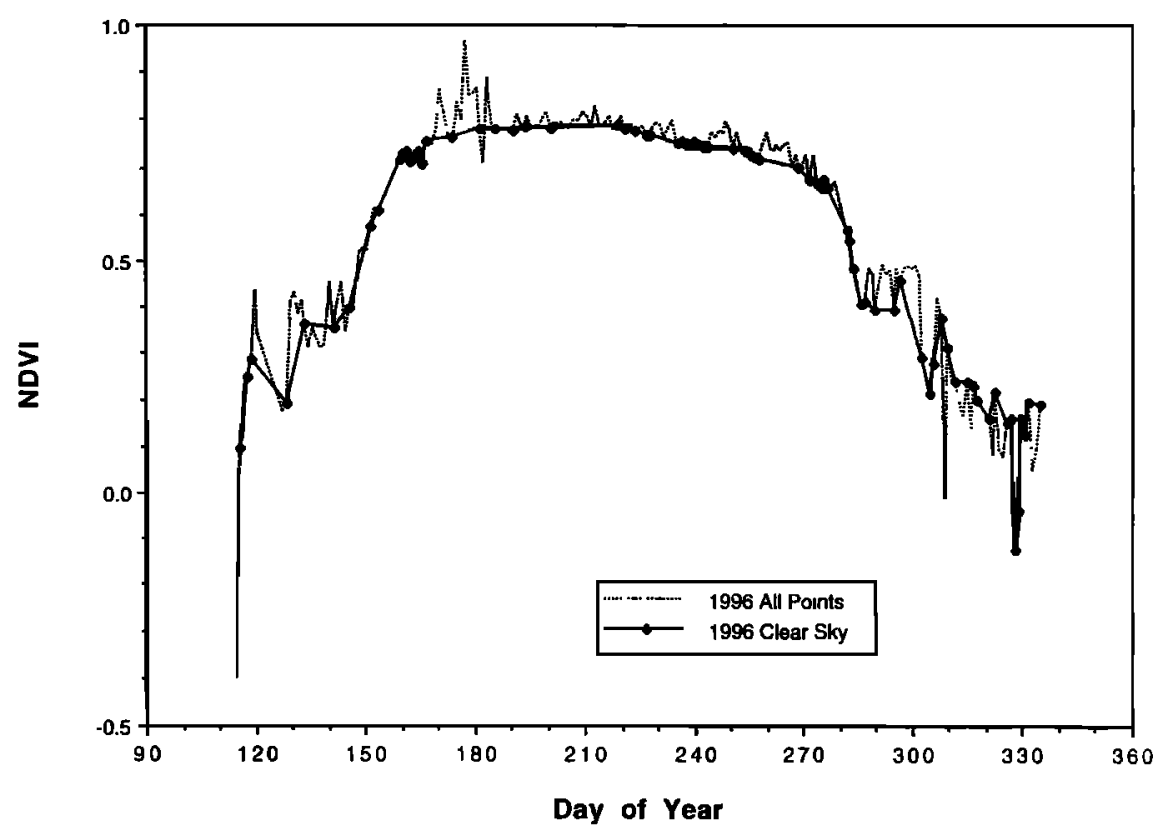

Figure 3. Daily NDVI observations of the BOREAS southern study area old aspen site for 1996. Observations for 1400 LT. Dotted line connects all observations. Solid line connects clear-day observations, plotted as solid diamonds. 


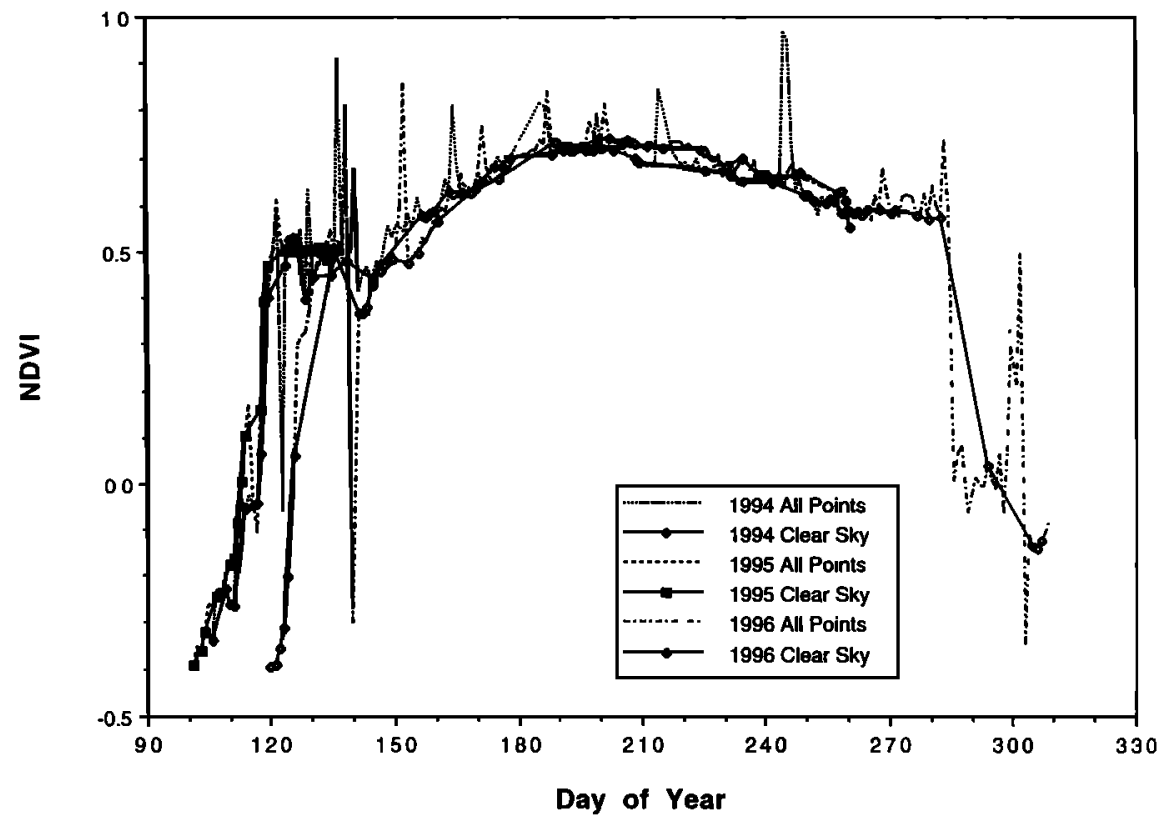

Figure 4. Daily NDVI observations of the BOREAS northern study area fen site for 1994, 1995, and 1996. Observations for 1400 LT. Dashed lines connect all daily observations. Solid lines connect clear-day observations, plotted with symbols.

VIs. After that, around day 300 (October 26) there is another sudden drop which may be due to snowfall.

This seasonal NDVI pattern is similar to the one observed with helicopter data of aspen forests in the Superior National Forest in Minnesota [Hall et al., 1992b]. However, the NDVI phenology, based on monthly composited AVHRR data shown by Steyaert et al. [1997], does not show the detailed features seen in the flux tower NDVI curve. The AVHRR data simply show a steady increase in NDVI from April to June, missing the step that occurs after snowmelt and before green-up.

The other deciduous site observed in this study is the fen, and it has a different seasonal NDVI pattern than the old aspen site. Figure 4 shows the NDVIs for the fen for 1994, 1995, and 1996. In 1995 a limited amount of data was collected,

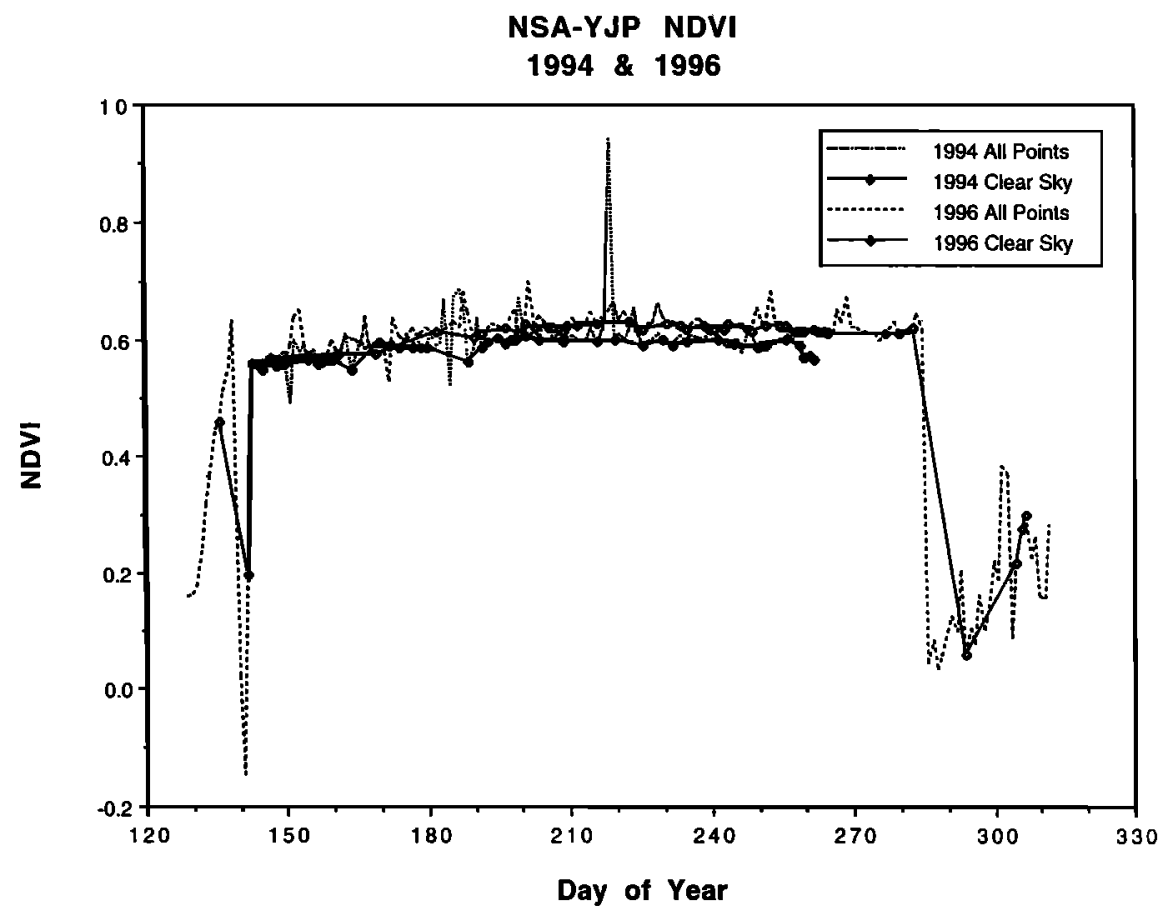

Figure 5. Daily NDVI observations of the BOREAS northern study area young jack pine site for 1994 and 1996. Observations for 1400 LT. Dashed lines connect all daily observations. Solid lines connect clear-day observations, plotted with symbols. 


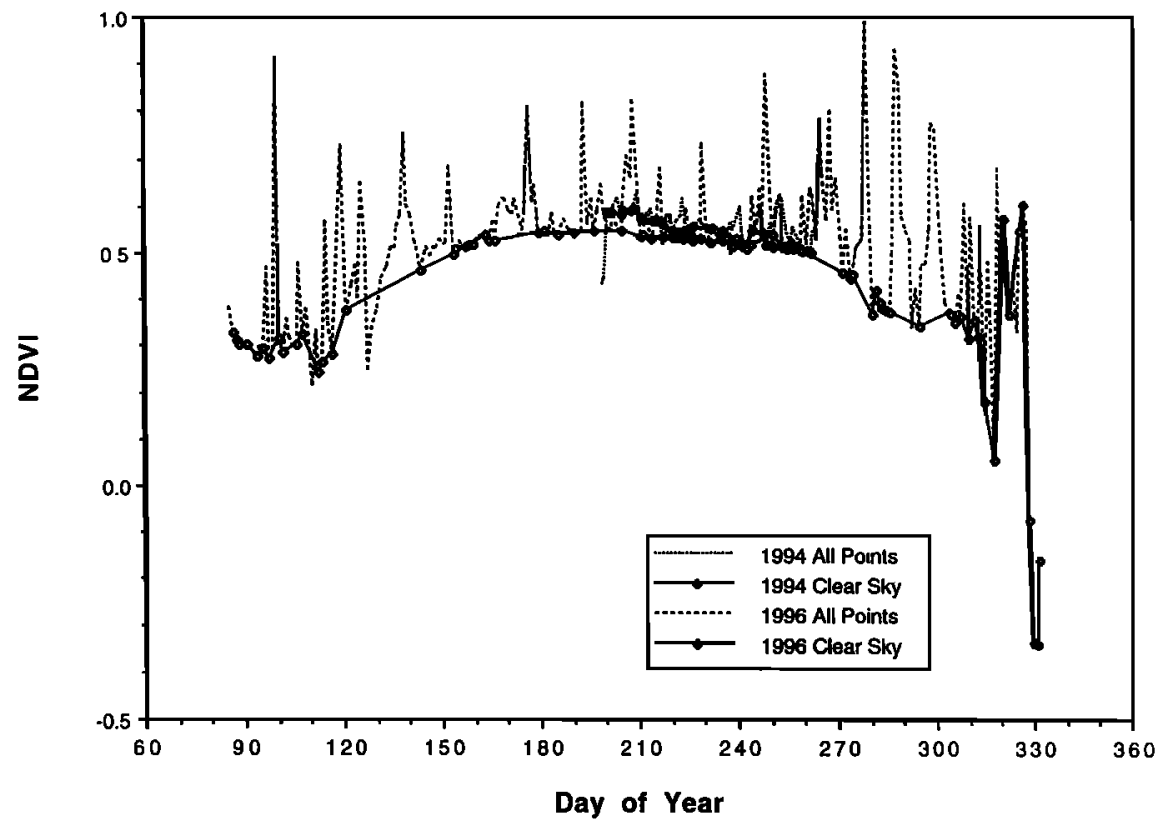

Figure 6. Daily NDVI observations of the BOREAS southern study area old black spruce site for 1994 and 1996. Observations for 1400 LT. Dashed lines connect all daily observations. Solid lines connect clear-day observations, plotted with symbols.

capturing only the thaw period. Note that the NDVI values for 1994 and 1996 are very close in value through the growing season. This is an indication, along with the general smoothness of the curves from the clear sky data, of the repeatability of this methodology.

As with the aspen site, all of the NDVI curves began with very low values, around -0.4 , indicative of snow cover. With snowmelt, NDVI rose quickly; in 1996 the snowmelt lagged the other two years by over 10 days. With the thaw of the snow, NDVI reached a value of around 0.5. In 1994 and 1996 there were sharp downward spikes in the unfiltered data during this period due to brief springtime snowfalls. Around day 142 (May 22) for both years there was a small dip, followed by the beginning of green-up. In 1996, NDVI increased from 0.46 to a midsummer high of 0.73 over 44 days. The NDVI remained fairly constant until day 231 (August 19) then began slowly decreasing out to day 283 (October 10). Following that, NDVI decreased from 0.57 to 0.04 due to snow.

The seasonal pattern for the fen is different than the aspen (see Figure 7). In the fen, green-up takes longer, 44 days compared to the aspen's 20 day green-up. The fen begins the green-up with a higher NDVI, 0.46 , than the leafless aspen

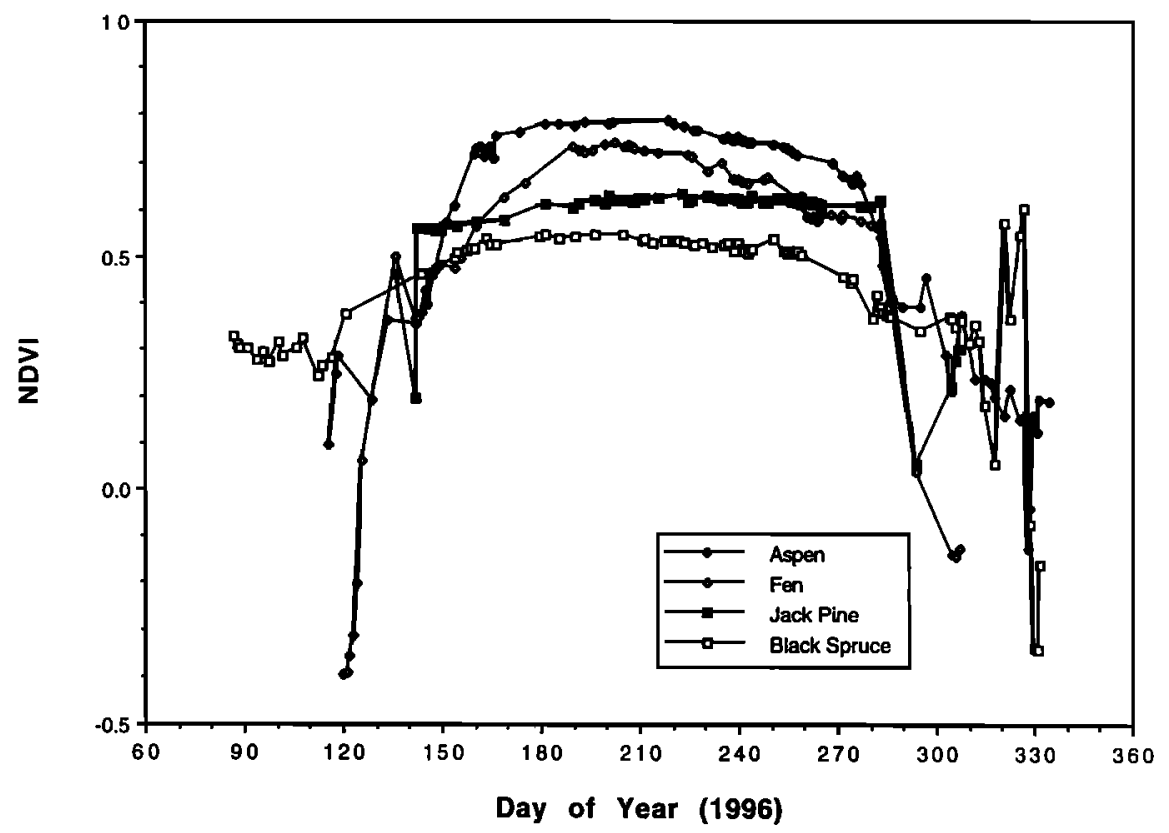

Figure 7. NDVI observations for clear days of four BOREAS sites for 1996. Observations for 1400 LT. 
NDVI of 0.35 . During the springtime green-up, both sites reach a maximum NDVI of about 0.73 , but the aspen continues a slow increase up to 0.79 , while the fen remains at that value. The pattern of the NDVI change during the green-up of the fen is similar to that of a grassland, as seen in FIFE [Hall et al., 1992; Goetz, 1997].

Turning from the deciduous fen site to the evergreen young jack pine site, there is again a different NDVI phenology (Figure 5). Notice that the late-spring snowfall on day 141 (May 21) of 1996 showed up as a downward spike, and a similar spike occurred in the data for the nearby fen site (Figure 4). Also, both sites had a large drop-off following day 285 (October 12). Both of these effects were most likely due to the two sites being hit by the same winter storms. Following the snowmelt, the NDVI curve for the young jack pine site was basically flat. The jack pines went through a seasonal change, but it was very subtle. In 1996 there was a green-up period from days 143 (May 23) to 223 (August 11), where NDVI went from 0.56 to 0.63 . After that the NDVI decreased very slightly until day 286 (October 13) when a snowfall caused a large drop.

Although another site dominated by conifers, the old black spruce phenology differs from the young jack pine (Figures 6 and 7). The black spruce site had a larger seasonal variation in NDVI and consistently smaller NDVI values than the jack pine site. The old black spruce site began springtime green-up on day 113 (April 23). This initial increase may have been due to snowmelt. At that time the NDVI value was 0.24 , higher than the other sites when snow covered. The high NDVI may be due to the instruments viewing a mixture of the green trees and snow-covered ground. From day 113 there was an increase in NDVI up through day 180 (June 29), when NDVI reached 0.55 . The curve remained flat for about 40 days and then began a slow decrease out to day 275 (October 2) when it started to drop off faster. NDVI remained near 0.36 from days 281 (October 8) to 313 (November 9). Following that period, NDVI values dropped, probably due to snowfall. There was a sudden upward jump between days 318 and 321 (November 14 and 17), and following that rise, NDVI values reached their highest values of the year. This may be due to the melting of the snow, coupled with the effect of large solar zenith angles. After day 328 (November 24) the NDVI values became negative. These values were very low because the instruments were viewing snow in the trees as well as on the ground.

The young jack pine data suggest that the seasonal change in NDVI for conifers is very small. If that is true for spruce, what accounts for the changes at the old black spruce site? Measurements of the spectral reflectance of understory components at this site were made in 1994 [Miller et al., 1997]. These measurements show a change in NDVI of the understory from spring to summer that is approximately as large as seen in the flux tower NDVIs. This observed change in the background reflectance may account for some of the seasonal variation in NDVI for this site.

The NDVI values, generated using micrometeorological instruments, show consistency in day-to-day clear sky observations, as well as in data collected in different years. Within the data, similarities between sites were observed in the response to snow-covered ground. These results suggest that this approach produces a measurement of NDVI that is consistent over time and between sites. The NDVI phenologies produced with this method provide both a spatial and a temporal detail unavailable from satellite data. The BOREAS data show that for four different boreal land cover types, each has a different seasonal NDVI pattern in both shape and midsummer maximum NDVI (Figure 7).

\section{Discussion}

The detailed NDVI phenologies presented here provide the opportunity to consider some of the causes of the seasonal patterns. Two examples are considered here, one looking at rates of change in leaf area in deciduous sites and the other examining the effects of varying solar zenith angles.

In the deciduous sites the period of most dramatic change is during the spring green-up. In the boreal forest the transition from winter senescence to springtime growth is a critical time. During this period the aspen and fen sites displayed different patterns of NDVI over time. The differences between the sites are clearly visible in the flux tower data, although the details would be smeared out in AVHRR phenologies. The aspen and fen NDVI patterns during green-up suggest different growth strategies for the vegetation of these two sites, one forested and one predominately herbaceous.

One method for exploring the relationship between NDVI and vegetation characteristics is through the use of radiative transfer models. Using the SAIL (scattering from arbitrarily inclined leaves) radiative transfer model the variations in NDVI with leaf area index (LAI) can be calculated [Verhoef, 1984; Goward and Huemmrich, 1992]. Through the model the effects on NDVI of three different modes of LAI growth with time have been considered: linear, logarithmic, and exponential. Changes in LAI over an arbitrary time period for each of these models of leaf growth are shown in Figure 8a-8c, along with the resulting NDVI values from the SAIL model. In these simulations all factors such as leaf and background optical properties and canopy structure were held constant, and only LAI was varied. This isolates only the effects of differing rates of leaf growth.

If the leaf area increases linearly with time, NDVI increases very rapidly at first, then flattens out as it begins to reach a saturation value (Figure 8a). A logarithmic increase in LAI, again produces a very rapid initial increase in NDVI, which then flattens out to a saturation value (Figure 8b). For exponential LAI growth, NDVI follows a more S-shaped trajectory, with the maximum NDVI values being reached more toward the end of the time period (Figure $8 \mathrm{c}$ ). This exercise indicates that when examining NDVI data, it would be difficult to determine if the growth rate of leaves is linear or logarithmic, as the basic shape of the NDVI curves are very similar for these two cases.

Comparing the SAIL model results with the NDVI observations suggests that the springtime leaf growth of the aspen stand was linear or logarithmic, while the herbaceous fen site had more of an exponential growth pattern. Further observations of green-up in other years experiencing different weather conditions or other sites with different vegetation types could further illuminate the differences in the growth rate of leaves in the spring.

Seasonal variation in NDVI may be due to factors other than changes in the vegetation, such as solar zenith angle variations. In general, the seasonal changes in solar zenith angle are similar to the seasonal course of deciduous vegetation growth, making it difficult to separate the effects of the two factors. Over the period of the NDVI data presented in this paper the solar zenith angle at $1400 \mathrm{LT}$ ranged between $33^{\circ}$ and $79^{\circ}$. Leblanc et al. [1997] modeled the effect of solar zenith angle on nadir-viewed NDVI for BOREAS sites. Their results show a 

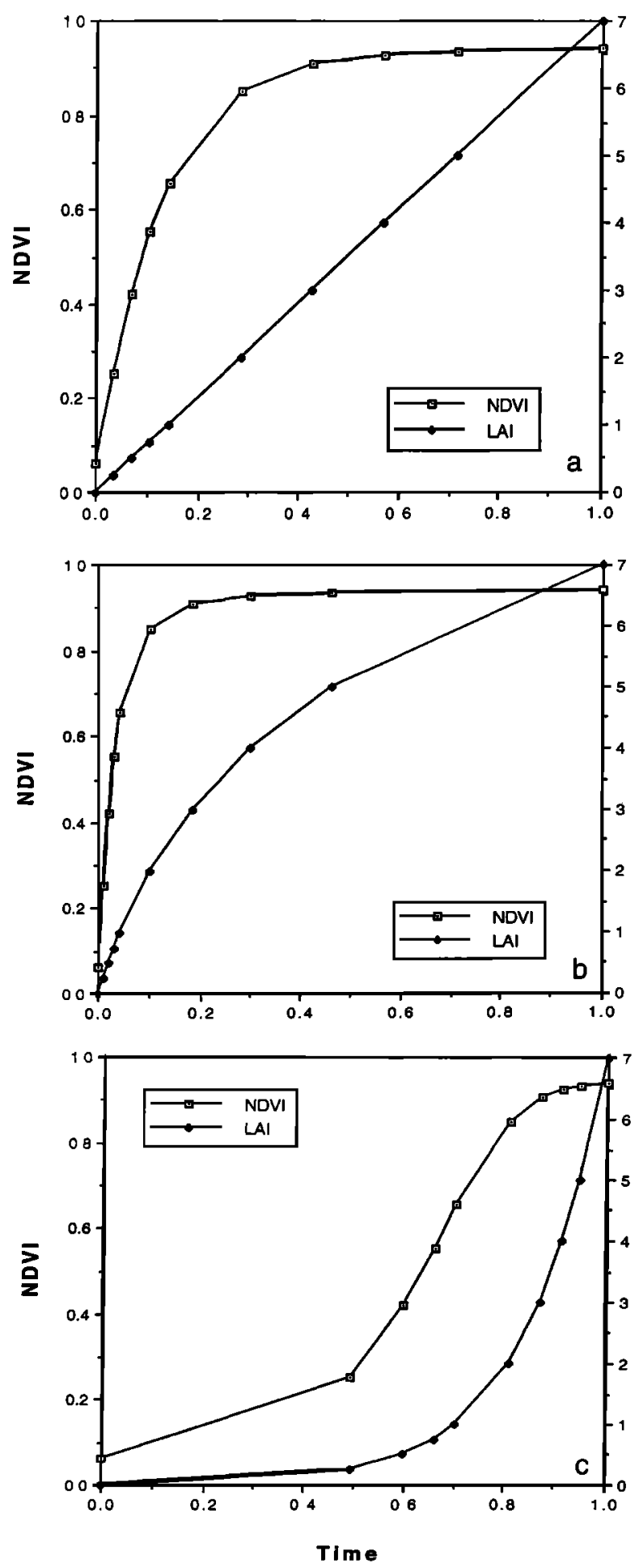

Figure 8. (a) Leaf area index, plotted as diamonds, varying linearly with time, and the resulting variation in NDVI, plotted as squares; (b) LAI varying logarithmically with time and the resulting variation in NDVI; (c) LAI varying exponentially with time and the resulting variation in NDVI. All NDVI values calculated from the SAIL model.

monotonic increase in NDVI with solar zenith angle. Over the range of solar zenith angles observed in these data the model indicated a change of 0.18 in NDVI. This raises questions in interpreting the NDVI data; however, the use of the radiation sensors provides a method to examine this effect.
Moore et al. [1996] performed an analysis of the effect of solar zenith angle for shortwave albedo of a red oak forest by examining data collected over individual days selected throughout the year. They found that shortwave albedo increased slightly with solar zenith angle for solar zenith angles less than $70^{\circ}$. They also observed differences in albedo between morning and afternoon observations with the same solar zenith angles.

Using the same approach as Moore et al. [1996], the effect of solar zenith angle variation was examined for the black spruce site. As the tower flux radiation sensors collected data continuously, this allows NDVI values to be calculated throughout the day. Thus NDVI values can be determined over a wide range of solar zenith angles within a single day. We assume that the variations in NDVI within the single day are not due to changes in the vegetation. Figure 9 shows the half hourly values of NDVI and incident PAR for day 165 (June 14). Day 165 was chosen because it was a clear day near the summer solstice, maximizing the range of solar zenith angles. The PAR data provide an indication of the course of the Sun through the day, with sunrise and sunset occurring when the incident PAR is zero. NDVI values were very large at dawn and dusk but fairly consistent through the middle of the day. There was a general downward trend in the NDVI through the midday and into the afternoon. The NDVI values are plotted against solar zenith angle for the half hourly data from day 165 and for the clear day values for all of 1996 in Figure 10. There are small differences between the morning and the afternoon NDVI values at the lower solar zenith values. The differences widen until at $70^{\circ}$ the difference is nearly 0.1 NDVI. This may be due to illumination differences caused by variations in the solar azimuth angle between morning and afternoon. Beyond a solar zenith angle of $70^{\circ}$ the flux tower NDVI begins to increase rapidly. Figure 9 displays much less of an effect of solar zenith angle on the tower flux NDVI compared to the results of Leblanc et al. [1997]. The disagreement may be due to the differences between a nadir view NDVI and the tower flux hemispherical NDVI.

The NDVI variations within a day can be contrasted with the seasonal variations to separate the effects of varying solar zenith angle from changes in the landscape. Through most of the year the daily values fall in the range of values from day 165. In the spring and autumn, values fall away from the half hourly values, suggesting changes in the landscape rather than effect of illumination variations. The large peak that occurred following day 318 is shown in Figure 10 to be within the range of values from day 165 , indicating the large NDVI values were due to the large solar zenith angles at that time of the year. Combining half hourly and daily values can be useful in separating out illumination effects from changes in the landscape, improving the usefulness of these data in detecting biological changes.

The small effect of variation in solar zenith angle on NDVI for a wide range of solar zenith angles at this site suggests that if needed, more daily values could be added to the seasonal curve. Values could be filled in for cloudy days that had been removed by using data collected during clear periods at other times during the day, as long as the solar zenith angle was not too large.

\section{Conclusions}

A method was described which can determine NDVI using existing micrometeorological instruments. This technique al- 


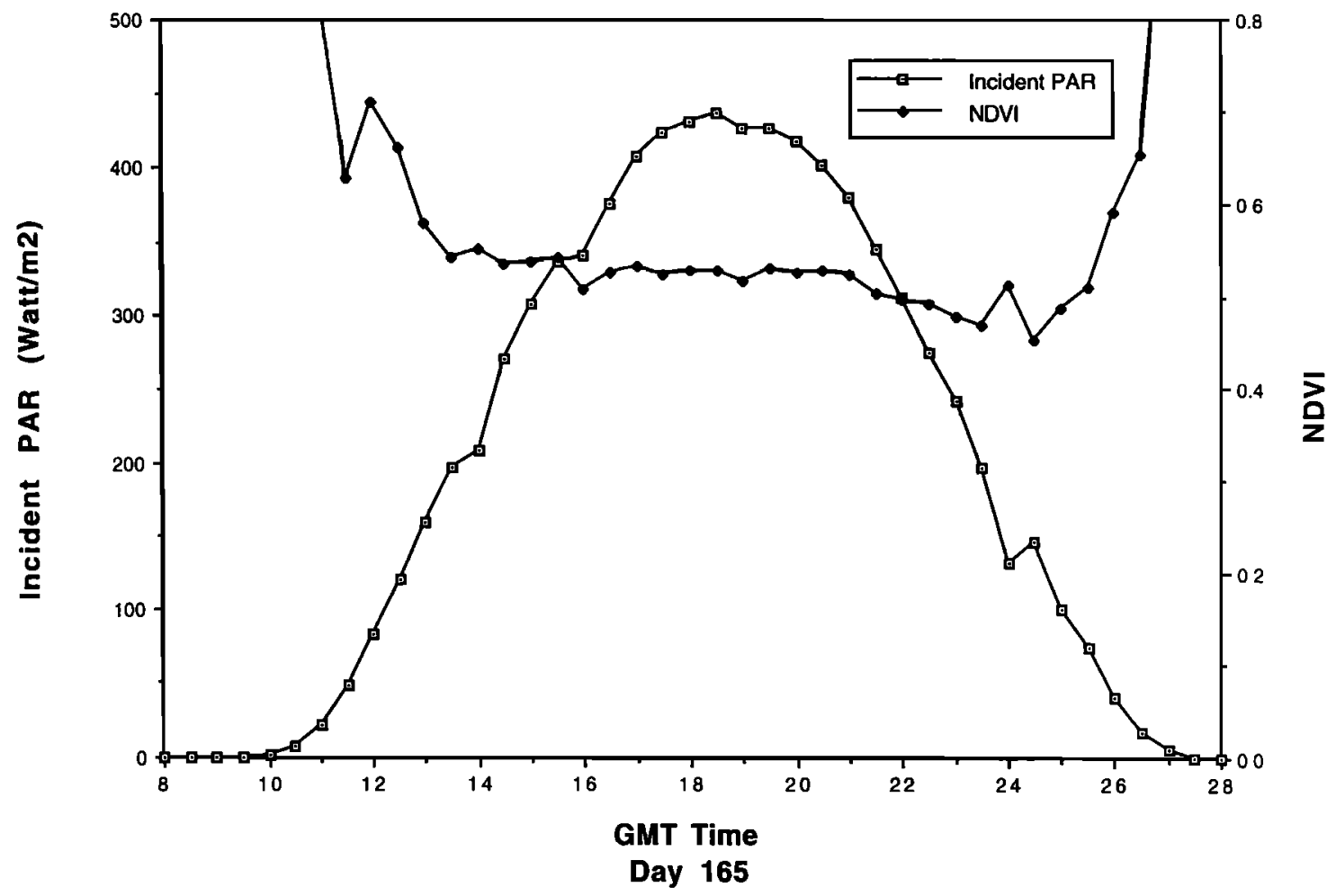

Figure 9. Half hourly values of NDVI, plotted as diamonds, and incident PAR, plotted as squares, for day 165 (June 14, 1996) for the BOREAS southern study area old black spruce site.

lowed the construction of temporally detailed NDVI phenologies for specific locations. NDVI phenologies generated for four different sites within the boreal forest biome showed that each different land cover has a unique form.

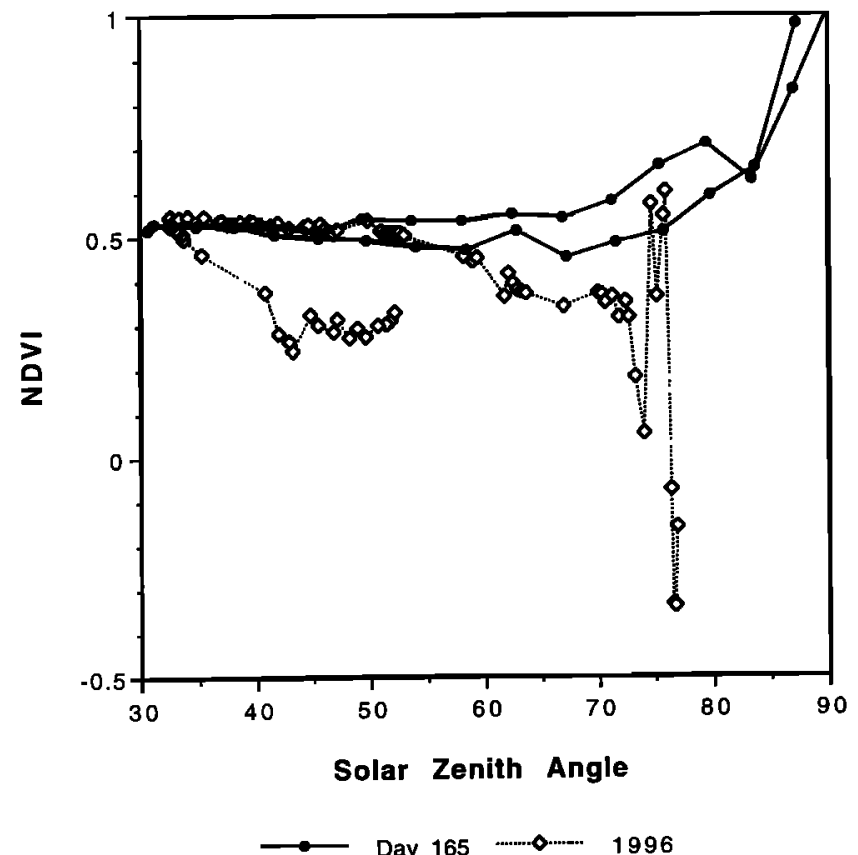

Figure 10. NDVI versus solar zenith angle at the BOREAS southern study area old black spruce site. Half hourly values of NDVI from day 165 (June 14, 1996), plotted as circles connected by a solid line, and 1996 daily clear-day NDVI observations for $1400 \mathrm{LT}$, plotted as diamonds connected by a dotted line.
This technique can help to improve understanding of the timing and nature of seasonal and multiyear variations in vegetation. Goulden et al. [1996] note that total seasonal carbon uptake of deciduous forests strongly depends on the timing of leaf out. Attempts to use remotely sensed approaches to accurately determine annual carbon budgets require an understanding of seasonal phenologies with a higher temporal resolution than can be presently provided by satellite data. NDVI from micrometeorological instruments can begin to develop a better understanding of the timing of seasonal vegetation changes. The use of NDVI provides a direct link between surface observations and satellite vegetation index data.

Acknowledgments. The authors wish to thank all who were involved in the collection and processing of the data used in this study. The instruments at the SSA OBS site were installed and monitored by S. E. Hale and S. L. Scott in 1994 and by M. B. Rayment and S. L. Scott in 1996. The data from both years were quality controlled and submitted to the database by J. M. Massheder. Instrument installation, data collection, and data processing for the NSA YJP and fen sites were performed by P. Lafleur, D. Joiner, P. Bartlett, A. Costello, B. Mantha, K. Boudreau, B. Robertson, D. Mueller, and L. Liblik. SSA OA data were collected with the assistance of Z. Nesic, U. Gramann, R. Ketler, P. Pacholek, and A. Barr. Thanks also go to the Saskatchewan Research Council, John Miller, and the RSS-19 team and Charlie Walthall and the RSS-3 team for the use of their data.

\section{References}

Badhwar, G. D., Use of Landsat-derived profile features for spring small-grains classification, Int. J. Remote Sens., 5(5), 783-797, 1984. Badhwar, G. D., R. B. MacDonald, F. G. Hall, and J. G. Carnes, Spectral characterization of biophysical characteristics in a boreal forest: Relationship between Thematic Mapper band reflectance and leaf area index for aspen, IEEE Trans. Geosci. Remote Sens., 24(3), 322-326, 1986. 
Black, T. A., et al., Annual cycles of water vapour and carbon dioxide fluxes in and above a boreal aspen forest, Global Change Biol., 2(3), 219-229, 1996.

Blair, B. O., and M. F. Baumgardner, Detection of green and brown wave in hardwood canopy covers using multi-date, multispectral data from Landsat-1, Agron. J., 69, 808-811, 1977.

DeFries, R. S., and J. R. G. Townshend, NDVI-derived land cover classifications at a global scale, Int. J. Remote Sens., 15(17), 35673586, 1994.

Field, C. B., J. T. Randerson, and C. M. Malmstrom, Global net primary production-Combining ecology and remote sensing, $R e$ mote Sens. Environ., 51(1), 74-88, 1995.

Goetz, S. J., Multi-sensor analysis of NDVI, surface temperature, and biophysical variables at a mixed grassland site, Int. J. Remote Sens., 18(1), 71-94, 1997.

Goetz, S. J., and S. D. Prince, Remote sensing of net primary production in boreal forest stands, Agric. For. Meteorol., 78(3), 149-179, 1996.

Goward, S. N., and D. G. Dye, Evaluating North American net primary productivity with satellite observations, Adv. Space Res., 7(11), 165174, 1987.

Goward, S. N., and K. F. Huemmrich, Vegetation canopy PAR absorptance and the normalized difference vegetation index: An assessment using the SAIL model, Remote Sens. Environ., 39, 119-140, 1992.

Goward, S. N., C. J. Tucker, and D. G. Dye, North American vegetation patterns observed with the NOAA-7 advanced very high resolution radiometer, Vegetatio, 64, 3-14, 1985.

Goward, S. N., A. Kerber, D. G. Dye, and V. Kalb, Comparison of North and South American biomes from AVHRR observations, Geocarto, 2(1), 27-40, 1987.

Goward, S. N., B. Markham, D. G. Dye, W. Dulaney, and J. Yang, Normalized Difference Vegetation Index measurements from the Advanced Very High Resolution Radiometer, Remote Sens. Environ., 35, 257-277, 1991.

Goulden, M. L., J. W. Munger, S.-M. Fan, B. C. Daube, and S. C. Wofsy, Exchange of carbon dioxide by a deciduous forest: Response to interannual climate variability, Science, 271(52556), 1576-1578, 1996.

Hall, F. G., and G. D. Badwar, Signature-extendible technology: Global space-based crop recognition, IEEE Trans. Geosci. Remote Sens., GE-25, 93-103, 1987.

Hall, F. G., D. B. Botkin, D. E. Strebel, K. D. Woods, and S. J. Goetz, Large scale patterns of forest succession as determined by remote sensing, Ecology, 72(2), 628-640, 1991.

Hall, F. G., K. F. Huemmrich, S. J. Goetz, P. J. Sellers, and J. E. Nickeson, Satellite remote sensing of surface energy balance: Success, failures, and unresolved issues in FIFE, J. Geophys. Res., 97, 19,061-19,090, 1992a.

Hall, F. G., K. F. Huemmrich, D. E. Strebel, S. J. Goetz, J. E. Nickeson, and K. D. Woods, Biophysical, Morphological, Canopy Optical Property, and Productivity Data From the Superior National Forest, NASA Tech. Memo. TM-104568, 1992b.

Holben, B. N., Characteristics of maximum-value composite images from temporal AVHRR data, Int. J. Remote Sens., 7, 1417-1434, 1986.

Jarvis, P. G., J. M. Massheder, S. E. Hale, J. G. Moncrieff, M. Rayment, and S. L. Scott, Seasonal variation of carbon dioxide, water vapor, and energy exchanges of a boreal black spruce forest, $J$. Geophys. Res., 102, 28,953-28,966, 1997.

Justice, C. O., J. R. G. Townshend, B. N. Holben, and C. J. Tucker, Analysis of the phenology of global vegetation using meteorological satellite data, Int. J. Remote Sens., 6(8), 1271-1381, 1985.

Lafleur, P. M., J. H. McCaughey, D. W. Joiner, P. A. Bartlett, and D. E. Jelinski, Seasonal trends in energy, water, and carbon dioxide fluxes at a northern boreal fen, J. Geophys. Res., 102, 29,009-29,020, 1997.

Leblanc, S. G., J. M. Chen, and J. Cihlar, NDVI directionality in boreal forests: A model interpretation of measurements, Can J. Remote Sens., 23(4), 369-380, 1997.

Loechel, S. E., C. L. Walthall, E. B. de Colstoun, J. Chen, B. L. Markham, and J. Miller, Variability of boreal forest reflectances as measured from a helicopter platform, J. Geophys. Res., 102, 29,49529,504, 1997.

Los, S. O., C. O. Justice, and C. J. Tucker, A $1^{\circ} \times 1^{\circ}$ global NDVI data set for climate studies derived from the GIMMS continental NDVI data, Int. J. Remote Sens., 15, 3493-3518, 1994.

Loveland, T. R., J. W. Merchant, D. O. Ohlen, and F. J. Brown, Development of a land cover characteristics database for the conterminous U. S., Photogramm. Eng. Remote Sens., 57(11), 1453-1463, 1991.

McCaughey, J. H., P. Lafleur, D. Joiner, D. Jelinski, and M. Ryan, Magnitudes and seasonal patterns of energy, water, and carbon exchanges at a boreal young jack pine forest in the BOREAS northern study area, J. Geophys. Res., 102, 28,997-29,008, 1997.

Miller, J. R., et al., Seasonal change in understory reflectance of boreal forests and influence on canopy vegetation indices, J. Geophys. Res., $102,29,475-29,482,1997$.

Moore, K. E., D. R. Fitzjarrald, R. K. Sakai, M. L. Goulden, J. W. Munger, and S. C. Wofsy, Seasonal variation in radiative and turbulent exchange at a deciduous forest in central Massachusetts, J. Appl. Meteorol., 35, 122-134, 1996.

Myneni, R. B., C. D. Keeling, C. J. Tucker, G. Asrar, and R. R. Nemani, Increased plant growth in the northern high latitudes from 1981 to 1991 , Nature, 386(6626), 698-702, 1997.

Prince, S. D., and S. N. Goward, Global primary production: A remote sensing approach, J. Biogeogr., 22(4-5), 815-835, 1995.

Running, S. W., and E. R. Hunt, Generalization of a forest ecosystem process model for other biomes, BIOME-BGC, and an application for global scale models, in Scaling Physiological Processes: Leaf to Globe, edited by J. R. Ehleringer and C. B. Field, pp. 141-158, Academic, San Diego, Calif., 1993.

Sakai, R. K., D. R. Fitzjarrald, and K. E. Moore, Detecting leaf area and surface resistance during transition seasons, Agric. For. Meteorol., 84, 273-284, 1997.

Sellers, P. J., et al., The Boreal Ecosystem-Atmosphere Study (BOREAS): An overview and early results from the 1994 field year, Bull. Am. Meteorol. Soc., 76, 1549-1577, 1995.

Sellers, P. J., et al., BOREAS in 1997: Experiment overview, scientific results and future directions, J. Geophys. Res., 102, 28,731-28,770, 1997.

Steyaert, L. T., F. G. Hall, and T. R. Loveland, Land cover mapping, fire regeneration, and scaling studies in the Canadian boreal forest with $1 \mathrm{~km}$ AVHRR and Landsat TM data, J. Geophys. Res., 102, 29,581-29,598, 1997.

Tucker, C. J., J. R. G. Townshend, and T. E. Goff, African land-cover classification using satellite data, Science, 227, 369-375, 1985.

Tucker, C. J., I. Y. Fung, C. D. Keeling, and R. H. Gammon, Relationship between $\mathrm{CO}_{2}$ variation and a satellite-derived vegetation index, Nature, 319, 195-199, 1986.

Verhoef, W., Light scattering by leaf layers with application to canopy reflectance modeling: The SAIL model, Remote Sens. Environ., 16, 125-141, 1984.

F. G. Hall and K. F. Huemmrich, NASA Goddard Space Flight Center, Code 923, Greenbelt, MD 20771. (Karl.Huemmrich@gsfc. nasa.gov)

T. A. Black, Department of Soil Science, University of British Columbia, Vancouver, B. C., Canada.

P. G. Jarvis, Institute of Ecology and Resource Management, University of Edinburgh, Edinburgh, Scotland EH8 NYL.

J. H. McCaughey, Department of Geography, Queen's University, Kingston, Ontario, Canada.

(Received August 16, 1998; revised January 26, 1999;

accepted March 4, 1999.) 